\title{
Risk for Coccidioidomycosis among Hispanic Farm Workers, California, USA, 2018
}

\author{
Stephen A. McCurdy, Catherine Portillo-Silva, Carol L. Sipan, Heejung Bang, Kirt W. Emery
}

To determine occupational risk factors for coccidioidomycosis among adult Hispanic outdoor agricultural workers in California, USA, we conducted a case-control study of workers seen at the Kern County medical facility and referred to the public health laboratory for coccidioidomycosis serologic testing. Participants completed an interviewer-administered health and work questionnaire. Among 203 participants (110 case-patients with positive and 93 controls with negative serologic results), approximately half were women, and more than three quarters were born in Mexico. Associated with coccidioidomycosis were self-reported dust exposure and work with root and bulb vegetable crops. A protective factor was leaf removal, an activity associated with grape cultivation. We conclude that subjective dust exposure and work with root and bulb vegetable crops are associated with increased risk for coccidioidomycosis among Hispanic farm workers. The agricultural industry should evaluate and promote dust-reduction measures, including wetting soil and freshly harvested products.

Ooccidioidomycosis (Valley fever or San Joaquin Valley fever) is a pulmonary and systemic infection that results from respiratory exposure to aerosolized arthroconidia spores of soil-dwelling species of Coccidioides fungi (1). Coccidioides fungi and coccidioidomycosis are strongly associated with the semiarid climate of the Lower Sonoran life zone of the southwestern United States and parts of Mexico, Central America, and South America. Most US cases occur in Arizona and California. However, the fungus and locally acquired cases have recently been reported as far north as Washington state, potentially related to changes in climate and land use patterns $(2,3)$. In

Author affiliations: University of California, Davis, California, USA (S.A. McCurdy, H. Bang); University of California, Merced, California, USA (C. Portillo-Silva, C.L. Sipan); Kern County Public Health Services Department, Bakersfield, California, USA (K.W. Emery)

DOI: https://doi.org/10.3201/eid2607.200024
California, the species most often implicated in human infection is C. immitis, whereas in Arizona it is $C$. posadasii $(2,3)$.

After an incubation period of $\approx 1-3$ weeks, most infected persons experience few or mild symptoms, and the condition usually resolves within weeks or months, often unrecognized $(4,5)$. Approximately $40 \%$ of infected persons experience an influenza-like illness with cough, fever, and fatigue that typically resolves without treatment. Approximately $1 \%$ of cases involve dissemination to skin, bone, meninges, and other tissues (6); patients with disseminated disease require long-term antifungal therapy and may die (7). Risk factors for disseminated disease include male sex, age $>60$ years, pregnancy, immunocompromise, and African and Filipino ancestry (8).

Case identification is based on clinically compatible illness with confirmatory laboratory evidence or skin-test conversion (9). Local health departments may find it impractical to obtain clinical information and thus may identify cases solely on the basis of laboratory results (4). Because most cases are subclinical, public health surveillance substantially underestimates infection risk. McCotter et al. estimated that the true number of cases is $\approx 4-6$-fold greater than that captured by public health surveillance (2).

Residence in or visits to coccidioidomycosis-endemic areas may lead to exposure and infection. The largest outbreaks have been associated with natural phenomena. A December 1977 dust storm in California's San Joaquin Valley (an area of high coccidioidomycosis endemicity, from which the disease derives its common name) resulted in a $\geq 10$-fold increase in incidence in 15 of the state's 58 counties $(1,10)$. The 1994 Northridge, California, earthquake was responsible for 203 outbreak-associated cases, including 3 deaths (11). Occupational risk has been associated with soil-disruptive activity involving archeologists (12), film crews (13), solar power farm construction workers $(14,15)$, roadway and construction workers 
$(16,17)$, and agricultural workers (18). Prison inmates in the San Joaquin Valley are also at increased risk, leading to a policy of excluding inmates with nonreactive spherulin-based coccidioidomycosis skin tests from these facilities (19).

In recent decades, coccidioidomycosis in California has increased markedly. Since individual case reporting began in 1995, the 2 highest years on record have been 2017 (7,658 cases) and 2018 (7,515 cases) (4). During 2000-2013, an average of 78 deaths/year were attributed to coccidioidomycosis in California (20), and during 2000-2011, $\approx 25,000$ hospitalizations were reported (21). The historically highest incidence among California counties has been in Kern County (2,937 cases in 2018, 323.2 cases/100,000 persons/ year), and several factors may contribute. First, the county is situated within the highly coccidioidomycosis-endemic San Joaquin Valley. Second, Kern is the most productive agricultural county in the nation (22), so soil disruption and exposure to agricultural dust are common. Third, Kern County leads the state by having had $\approx 116,000$ hired farm workers in 2014 (23). Although Hispanic origin has not been shown to be an independent risk factor for coccidioidomycosis (8), and to our knowledge no outbreaks in this group have been reported, $\approx 95 \%$ of hired crop workers in California are Hispanic (24) and thus represent a large occupational risk group.

Despite longstanding recognition of agricultural work as an occupational risk factor for coccidioidomycosis, little research to identify specific high-risk agricultural exposures, such as crops or tasks, has been conducted. We therefore conducted a case-control study of coccidioidomycosis in Hispanic farm workers in Kern County, California, focused on identifying occupational risks. We tested the hypothesis that subjective dust exposure is related to risk for infection and conducted exploratory analyses to identify associated crops and tasks.

\section{Materials and Methods}

\section{Study Design}

For this case-control study, we used data collected from June 1, 2016, through August 31, 2018. During this period, the Kern County Public Health Services Department provided a list, approximately monthly, of persons who had undergone serologic testing for coccidioidomycosis at the Kern County Public Health Laboratory after referral from Kern Medical, the county public healthcare organization where local Hispanic agricultural workers are likely to seek care. Kern Medical comprises a 222-bed teaching hospital and clinics providing primary and specialty care for an ethnically diverse population. Kern Medical has longstanding expertise with coccidioidomycosis and hosts the Valley Fever Institute (25) to promote education, treatment, and research on coccidioidomycosis.

\section{Study Sample}

To assess candidacy for our study, we made up to 10 attempts to contact by telephone all persons referred from Kern Medical for coccidioidomycosis serologic testing who were $\geq 18$ years of age and had $\geq 1$ positive serologic test result (potential cases) and a random sample of persons with all negative serologic test results (potential controls). We invited to complete a full in-person interview those screened persons with self-declared Hispanic or Latino origin who had worked in outdoor agriculture in Kern County for $\geq 1$ month in the preceding year, were not incarcerated, and were able to provide informed consent in Spanish or English. We initially excluded women who had been pregnant in the past year because Kern Medical uses coccidioidomycosis testing for screening of pregnant women rather than for diagnosis of suspected illness. However, because of low enrollment, we removed the pregnancy exclusion and considered as study candidates all persons who had undergone coccidioidomycosis serologic testing after referral from Kern Medical. Participants received a gift certificate for \$15 in appreciation for their time. The University of California Davis Institutional Review Board approved and monitored the study (IRBNet ID 747508).

\section{Definitions}

Serologic evaluation comprised 3 tests: immunodiffusion for IgM, immunodiffusion for IgG, and complement fixation (considered positive for dilutions $\geq 1: 2$ ). Case-patients were defined as persons with $\geq 1$ positive serologic test result. Control status was assigned to persons with negative results for all 3 serologic tests.

\section{Questionnaire Development and Administration}

We reviewed available survey instruments from previous outbreak investigations in Kern and San Joaquin Counties (26) and incorporated relevant material into our questionnaire. Colleagues in the California Department of Public Health and the Centers for Disease Control and Prevention reviewed questionnaire drafts. We pilot tested the questionnaire with a sample of 20 Hispanic agricultural workers in Kern County and excluded those persons from this report. The final questionnaire addressed demographic characteristics; health history; and agricultural work history with job start and end dates for the preceding 
year, weekly hours, frequency of outdoor work, crop or commodity, tasks, subjective dust exposure, and frequency of use in dusty conditions for personal respiratory protective measures and soil wetting. We separated jobs by change in location and task. After obtaining informed consent, trained study staff fluent in Spanish and English and blinded to participant case status administered the questionnaire in each participant's home or in the study office.

\section{Exposure Assessment}

Participants whose jobs involved a specific crop or task were considered to have been exposed to that crop or task; we added the total weeks of exposure over all jobs in the preceding year. We combined crops into 3 categories based on likely exposure to potentially infectious soil dusts: root and bulb vegetables growing underground (beets, carrots, garlic, onions, radishes, sweet potatoes), near-ground crops (blueberries, chili peppers, cotton, grapes, kale, lettuce, spinach, strawberries, tomatoes, watermelons), and tree crops (almonds, apples, apricots, cherries, kiwis, oranges and Mandarin oranges, pomegranates, pistachios). We also examined individual crops and tasks reported by $\geq 9 \%$ of participants. Dust exposure was based on response to the question: "How often did/does your work at this job generate a lot of dust?" Responses were "never/sometimes/half of the time/ most of the time/always." For final analyses, we dichotomized these responses as "never/sometimes" versus "half of the time/most of the time/always." These responses were also used for mask use ("When working in dusty conditions, how often did/do you wear a mask?") and frequency of soil wetting ("When working in dusty conditions, how often is/was the soil kept wet to reduce dust?").

\section{Data Management and Analysis}

Data from the paper questionnaires were doubleentered into a computer database; discrepancies were checked against the paper questionnaire and corrected. Subsequently, a 20\% sample of randomly selected questionnaires was checked against the digital database; 6 entry errors among 223 variables per questionnaire were identified and corrected (error rate $<0.15 \%$ ).

We analyzed data by using Stata 15.1 (https:/ / www.stata.com). We summarized distributions of continuous variables with either means and SDs (for approximately bell-shaped distributions) or medians and interquartile ranges (IQRs). We summarized categorical variables as percentages within each category. For group comparisons, we used the Fisher exact test for nonordinal categorical variables and the Kruskal-Wallis test for continuous and ordinal categorical variables.

We initially examined 2-dimensional tables of case status by selected occupational and demographic characteristics and used the Stata logistic command to derive unadjusted odds ratios (ORs), with subsequent adjustments for age and sex. We assessed robustness by comparing adjusted odds ratios from the entire sample with those derived among men and women separately, after removing from analysis women reporting a pregnancy in the preceding year and persons reporting no symptoms.

\section{Results}

\section{Study Sample and Demographic Characteristics:}

We screened 1,803 (51\%) of 3,509 persons selected from the Kern County Public Health Services Department periodic lists of coccidioidomycosis testing referrals. Reasons for not screening were wrong numbers or failure to connect after 10 attempts $(\approx 75 \%)$, language or communication difficulty $(\approx 15 \%)$, or the person declining to be screened $(\approx 10 \%)$. Of those screened, $380(21 \%)$ persons were eligible; of those, 215 (57\%) completed an interview. Participation was higher for case-patients $(70 \%)$ than for controls $(48 \% ; p=0.0001)$. Of those interviewed, 203 (110 case-patients and 93 controls) were subsequently confirmed as eligible and included in our sample (Table 1). The major reasons for postinterview disqualification were lack of qualifying agricultural work and indeterminate serologic test results. Median time from testing to interview was 39 (IQR 25-55) days.

Women represented a greater proportion of controls $(57 \%)$ than of case-patients $(42 \%) ; \mathrm{p}=0.04)$. Female controls were also significantly younger than male controls and case-patients of each sex ( $p=$ 0.03 ). More than three quarters of participants were born in Mexico, and $\approx 85 \%$ completed the interview in Spanish. Median time living in Kern County was $>10$ years. Median annual family income was in the $\$ 15,001-\$ 20,000$ category, and most participants had completed $\leq 9$ years of formal education. Pregnancy within the past year was less frequent among female case-patients $(27 \%)$ than female controls $(74 \% ; p=0.0001)$.

\section{Occupational Characteristics}

Case-patients and controls were comparable for number of jobs (median 3), weeks worked in outdoor agriculture in the preceding year (median 30 ), 
and weekly work hours in the most recent job (median 48). A significantly higher percentage of casepatients $(21 \%)$ than controls $(9 \%)$ worked with root and bulb vegetable crops ( $p=0.02$; Table 2$)$. The most frequently worked crop was grapes, worked less frequently by case-patients (58\%) than controls (72\%; p $=0.06$ ). Case-patients and controls were comparable with respect to agricultural tasks, with the exception of leaf removal, which was performed significantly less frequently by case-patients $(23 \%)$ than controls $(40 \% ; \mathrm{p}=0.01)$.

Always working outdoors was reported by $94 \%$ of participants. With respect to the most recent job, significantly more case-patients $(71 \%)$ than controls $(56 \%)$ reported dust exposure for half of the time or more $(p=0.02)$, whereas mask use and soil wetting in dusty conditions on a half-time or more basis were comparable among case-patients and controls, reported by approximately half of participants. Neither mask use nor soil wetting were independently associated with self-reported dust exposure. Among 117 persons reporting any mask use, 102 (87\%) reported wearing a bandana, 7 (6\%) using an N95 respirator, and $1(1 \%)$ wearing a half-face mask. Women were markedly more likely than men to report mask use (77\% vs. $27 \%$; $\mathrm{p}=0.0001$ ).

\section{Associations between Occupational Exposures and Coccidioidomycosis}

Age- and sex-adjusted ORs for having coccidioidomycosis (Table 2) were significantly elevated for self-reported dust exposure (OR 1.9, 95\% CI 1.03.5 ) and work with root and bulb vegetables (OR 3.0, 95\% CI 1.2-7.1). Exploratory analysis of hours worked with root and bulb vegetable crops did not show a dose response, although 95\% CIs were wide. For work with root and bulb vegetables, the OR for work with carrots was also elevated (OR 2.9, 95\% CI 1.0-8.6). ORs were reduced for those who worked with grapes $(0.6,95 \%$ CI $0.3-1.0)$ and leaf removal (OR 0.4, 95\% CI 0.2-0.8). Mask use and soil wetting in dusty conditions were associated with modest and statistically nonsignificant reductions in ORs. Patterns were similar for men and women separately and after excluding women pregnant in the prior year (12 cases, 39 controls) and persons reporting no clinical features of coccidioidomycosis (4 cases, 16 controls).

\section{Clinical Characteristics}

Case-patients were significantly more likely than controls to report clinical features associated with coccidioidomycosis (Table 3); adjusted ORs ranged from
2.6 (weight loss) to 4.3 (shortness of breath). The most frequent signs/symptoms among all participants were fatigue and cough. Case-patients reported significantly greater median weight loss $(10 \mathrm{vs} .0 \mathrm{lb} ; \mathrm{p}=$ $0.003)$ and lost workdays ( 18.5 vs. $0 \mathrm{~d} ; \mathrm{p}=0.0001)$ than did controls. Case-patients had $>2$-fold increased odds of being hospitalized.

Table 1. Selected demographic and health characteristics of 203 Hispanic farm workers evaluated for coccidioidomycosis, Kern County, California, USA, 2016-2018*

\begin{tabular}{|c|c|c|}
\hline Characteristic & $\begin{array}{c}\text { Case-patients, } \\
\mathrm{n}=110\end{array}$ & $\begin{array}{c}\text { Controls, } \\
n=93\end{array}$ \\
\hline \multicolumn{3}{|l|}{ Sex, no. (\%) } \\
\hline $\mathrm{F}$ & $46(42)$ & $53(57)$ \\
\hline M & $64(58)$ & $40(43)$ \\
\hline \multicolumn{3}{|l|}{ Age, y } \\
\hline \multicolumn{3}{|l|}{ Median } \\
\hline $\mathrm{M}$ & 38.7 & 42.0 \\
\hline $\mathrm{F}$ & 38.1 & 32.7 \\
\hline \multicolumn{3}{|l|}{ IQR } \\
\hline M & $29.6-47.8$ & $29.0-50.5$ \\
\hline $\mathrm{F}$ & $28.5-46.3$ & $27.0-39.5$ \\
\hline \multicolumn{3}{|l|}{ Country of birth, no. (\%) } \\
\hline Mexico & $83(76)$ & $74(80)$ \\
\hline United States & $16(15)$ & $16(17)$ \\
\hline Central America & $11(10)$ & $3(3)$ \\
\hline \multicolumn{3}{|c|}{ Language used during interview, no. (\%) } \\
\hline Spanish & $94(85)$ & $80(86)$ \\
\hline English & $16(15)$ & $13(14)$ \\
\hline \multicolumn{3}{|l|}{ Years lived in United States } \\
\hline \multicolumn{3}{|c|}{ Median } \\
\hline M & 18.7 & 23.2 \\
\hline $\mathrm{F}$ & 18.0 & 16.6 \\
\hline \multicolumn{3}{|l|}{ IQR } \\
\hline$M$ & $13.2-27.4$ & $14.8-32.7$ \\
\hline $\mathrm{F}$ & $12.5-23.3$ & $9.6-20.3$ \\
\hline \multicolumn{3}{|l|}{ Years lived in Kern County } \\
\hline \multicolumn{3}{|l|}{ Median } \\
\hline $\mathrm{M}$ & 11.2 & 16.8 \\
\hline $\mathrm{F}$ & 14.0 & 11.6 \\
\hline \multicolumn{3}{|l|}{ IQR } \\
\hline$M$ & $5.6-21.5$ & $10.7-26.2$ \\
\hline $\mathrm{F}$ & $7.2-14.9$ & $4.7-17.0$ \\
\hline \multicolumn{3}{|l|}{ Years of education } \\
\hline Median & 7.5 & 9.0 \\
\hline IQR & $6-12$ & $6-12$ \\
\hline \multicolumn{3}{|c|}{ Annual family income, US \$, no. (\%) } \\
\hline$\leq 9,000$ & $17(15)$ & $11(12)$ \\
\hline$\overline{9}, 001-12,000$ & $15(14)$ & $10(11)$ \\
\hline $12,001-15,000$ & $13(12)$ & $17(18)$ \\
\hline $15,001-20,000$ & $12(11)$ & $15(16)$ \\
\hline$\geq 20,001$ & $24(22)$ & $20(22)$ \\
\hline Not stated & $29(26)$ & $20(22)$ \\
\hline \multicolumn{3}{|l|}{ Smoker status, no. (\%) } \\
\hline Never & $80(73)$ & $65(70)$ \\
\hline Former & $27(25)$ & $22(24)$ \\
\hline Current & $3(3)$ & $6(6)$ \\
\hline \multicolumn{3}{|c|}{ Selected health conditions, no. (\%) } \\
\hline Diabetes & $20(18)$ & $17(18)$ \\
\hline Asthma & $5(5)$ & $7(8)$ \\
\hline Other lung conditions & $31(28)$ & $17(18)$ \\
\hline Cancer & $5(5)$ & $7(8)$ \\
\hline Pregnancy† & $12(27)$ & $39(74)$ \\
\hline
\end{tabular}

${ }^{*} \mathrm{QQR}$, interquartile range.

†Percentage calculations based on women only. 


\section{Discussion}

We report the results of a case-control study that examined potential occupational risk factors for coccidioidomycosis among Hispanic agricultural workers in Kern County, California. Self-reported dust exposure was significantly associated with a near doubling of the odds of coccidioidomycosis, and odds were increased a significant 3-fold for those who worked with root and bulb vegetable crops. Leaf removal, a task almost uniquely limited to grape cultivation, was associated with a significant $60 \%$ reduction in odds. Mask use (chiefly cloth bandanas) and soil wetting was associated with modest and statistically nonsignificant reductions of odds of coccidioidomycosis. The clinical findings illustrate a heavy health burden. The most prevalent symptom was fatigue or weakness, reported by $\approx 80 \%$ of cases and associated with a median 18.5 days of lost work time. Those lost days accounted for $\approx 10 \%$ of the 213 average annual workdays for California farm workers in 2015-2016 (24) and represent an income loss few can afford.

The association with self-reported dust exposure is consistent with the mechanism of exposure, whereby aerosolized Coccidioides spores are inspired and establish infection in the lung. Thus, time spent outdoors, where wind may carry dust and spores from on site or afar, is an environmental risk for the general population in coccidioidomycosis-endemic areas and especially for persons whose work is outdoors or involves soil disruption (27). The largest occupational risk group is agricultural workers. In 2014, there were an estimated 829,300 hired agricultural workers in California (23); $\approx 95 \%$ were Hispanic (24). Thus, Kern County and the San Joaquin Valley represent the confluence of multiple factors contributing to the public health effects of coccidioidomycosis: environmental conditions favorable to growth and aerosolization of Coccidioides spores, predominance of agriculture with concomitant soil disruption in an outdoor work setting, and a large population of occupationally exposed persons.

With this study, we aimed to identify specific agricultural exposures and practices affecting risk. We observed a 3-fold increase in the odds of coccidioidomycosis among root and bulb vegetable crop workers, although a dose-response phenomenon

\begin{tabular}{|c|c|c|c|}
\hline Characteristic & Cases, no. $(\%), n=110$ & Controls, no. $(\%), n=93$ & $\begin{array}{c}\text { Adjusted odds ratio } \\
(95 \% \mathrm{Cl})^{*}\end{array}$ \\
\hline \multicolumn{4}{|c|}{ Self-reported dust exposure for most recent job } \\
\hline Never or sometimes & $32(29)$ & $41(44)$ & Reference \\
\hline Half time or more & $78(71)$ & $52(56)$ & $1.9(1.0-3.5)$ \\
\hline \multicolumn{4}{|l|}{ Work in crop category in past yeartł } \\
\hline Root and bulb vegetable crops $† \ddagger$ & $23(21)$ & $8(9)$ & $3.0(1.2-7.1)$ \\
\hline Near-ground crops $\uparrow \S$ & $76(69)$ & $76(81)$ & $0.5(0.3-1.0)$ \\
\hline Tree crops十ा & $60(55)$ & $41(44)$ & $1.4(0.8-2.5)$ \\
\hline \multicolumn{4}{|l|}{ Work with specified crop in past year†\# } \\
\hline Grapes & $64(58)$ & $67(72)$ & $0.6(0.3-1.0)$ \\
\hline Almonds & $24(22)$ & $17(18)$ & $1.1(0.5-2.3)$ \\
\hline Mandarin oranges & $23(21)$ & $19(20)$ & $1.1(0.5-2.1)$ \\
\hline Carrots & $14(13)$ & $5(5)$ & $2.9(1.0 .8 .6)$ \\
\hline \multicolumn{4}{|l|}{ Tasks performed in past yearf ${ }^{\star *}$} \\
\hline Harvest & $82(75)$ & $68(73)$ & $1.3(0.7-2.5)$ \\
\hline Pruning & $40(36)$ & $39(42)$ & $0.7(0.4-1.3)$ \\
\hline Packing (outdoor) & 39 (35) & $33(35)$ & $1.2(0.6-2.1)$ \\
\hline Leaf removal & $25(23)$ & $37(40)$ & $0.4(0.2-0.8)$ \\
\hline Weeding & $14(13)$ & $10(11)$ & $1.3(0.5-3.1)$ \\
\hline Irrigation & $15(14)$ & $7(8)$ & $1.6(0.6-4.2)$ \\
\hline \multicolumn{4}{|l|}{ Mask use for most recent job } \\
\hline Never or sometimes & $58(53)$ & $40(43)$ & Reference \\
\hline Half the time or more & $51(47)$ & $53(57)$ & $0.9(0.5-1.7)$ \\
\hline \multicolumn{4}{|c|}{ Soil wetting in dusty conditions for most recent job } \\
\hline Never or sometimes & $63(58)$ & $48(52)$ & Reference \\
\hline Half the time or more & $46(42)$ & $45(48)$ & $0.8(0.4-1.3)$ \\
\hline
\end{tabular}

${ }^{*}$ Adjusted for age and sex.

†Categories are not mutually exclusive; reference group is all participants not working in specified category.

†Root and bulb vegetables growing underground: beets, carrots, garlic, onions, radishes, sweet potatoes.

§Near-ground crops: cotton and fruits and vegetables growing above ground and near the surface, including blueberries, chili peppers, grapes, kale,

lettuce, spinach, strawberries, tomatoes, watermelon.

१Tree crops: almonds, apples, apricots, cherries, kiwi, oranges and Mandarin oranges, pomegranates, pistachios.

\#Limited to crops reported by $\geq 9 \%$ of participants; crops are not mutually exclusive.

** Limited to tasks reported by $\geq 9 \%$ of participants; tasks are not mutually exclusive. 
Table 3. Reported clinical characteristics among 203 Hispanic farm workers evaluated for coccidioidomycosis, Kern County, California, USA, 2016-2018

\begin{tabular}{|c|c|c|c|}
\hline Clinical characteristic & Cases, no. (\%), $n=110$ & Controls, no. (\%), $n=93$ & Adjusted odds ratio $(95 \% \mathrm{Cl})^{*}$ \\
\hline$\geq 1$ clinical characteristic & $100(91)$ & $72(77)$ & $4.4(1.4-14.2)$ \\
\hline Fatigue or weakness & $91(83)$ & $52(56)$ & $3.7(1.9-7.2)$ \\
\hline Cough & $74(67)$ & $38(41)$ & $3.0(1.6-5.3)$ \\
\hline Night sweats & $73(66)$ & $34(37)$ & $3.2(1.8-5.8)$ \\
\hline Weight loss $\dagger$ & $73(66)$ & $40(43)$ & $2.6(1.4-4.7)$ \\
\hline Fever & $72(65)$ & $29(31)$ & $4.0(2.2-7.4)$ \\
\hline Chest pain & $71(65)$ & $29(31)$ & $3.8(2.1-7.0)$ \\
\hline Shortness of breath & $66(60)$ & $25(27)$ & $4.3(2.3-7.9)$ \\
\hline Difficulty breathing & $66(60)$ & $34(37)$ & $2.8(1.5-4.9)$ \\
\hline Hospitalized $\ddagger$ & $52(47)$ & $24(26)$ & $2.3(1.2-4.4)$ \\
\hline Missed work§ & $88(80)$ & $45(48)$ & $4.0(2.1-7.7)$ \\
\hline
\end{tabular}

${ }^{*}$ Adjusted for age and sex.

†Median (interquartile [IQR]) weight loss, in pounds, by case-patients vs. controls $10(0-18)$ vs. $0(0-10) ; p=0.003$, Kruskal-Wallis test.

$\ddagger$ Median (IQR) nights hospitalized for case-patients vs. controls $0(0-5)$ vs. $0(0-1) ; p=0.002$, Kruskal-Wallis test.

$\S$ Median (IQR) days of work lost by case-patients vs. controls $18.5(2-48)$ vs. $0(0-24) ; p=0.0001$, Kruskal-Wallis test.

was not evident. The mechanism behind the observed increased risk may relate to dust exposure during cultivation and harvest. Harvest typically is mechanized, but workers may be involved in handling and shaking off surface and subsurface dirt, potentially bearing infectious Coccidioides spores, from freshly harvested product as it is prepared for transport and market. Similarly, reduced risk associated with leaf removal and work with grapes may be mediated through less frequent work with other crops and tasks associated with exposure to dust from surface and subsurface dirt.

Mask use and soil wetting showed modest and statistically nonsignificant protective effects. Mask use, chiefly with a pañuelo, a cloth bandana covering the mouth and nose, is primarily reported by women, here and in other studies (28). Cloth bandanas are of limited effectiveness for respiratory protection (29), and educational campaigns should focus on limiting work under dusty conditions and promoting use of National Institute for Occupational Safety and Health (NIOSH)-approved respirators with particulate filters rated N95, N99, N100, P100, or HEPA when such work is necessary. Unfortunately, compliance may be reduced by the practical challenges of using personal respiratory protection, including discomfort and interference with speed and workflow.

A limitation of this study is low power due to sample size, limiting exploration of confounding as a possible contributor to observed associations. For example, associations between crop or task and disease risk could be confounded by sociodemographic and other factors that may channel susceptible persons to certain crops and work activities. Sample size also affected precision and subgroup analyses, yet we nevertheless found statistically significant associations for subjective dust exposure, work with root and bulb vegetables, and leaf removal and nonsignificant findings in the expected direction of effect for mask use and soil wetting. These findings suggest the need for focused studies looking at dust exposure and disease risk in association with specific crops and activities and efficacy of protective programs.

We originally planned to limit participation to persons referred for Coccidioides serologic testing because of clinical indications of disease. However, it was not feasible for the Kern County Public Health Services Department to document clinical features as recommended by the Council of State and Territorial Epidemiologists (9), and case identification was based solely on serologic test results. Moreover, women seen for obstetric care at Kern Medical are referred for coccidioidomycosis serologic testing as a screening measure. However, exploratory and sensitivity analyses, in which we examined men and women separately and removed women reporting pregnancy in the preceding year and persons without reported clinical features, did not materially change our findings.

Selection bias may also have affected our results in several ways. First, the sample was limited to persons working in Kern County. Although the study population was demographically similar to published descriptions (24) of California Hispanic farm workers, it is possible that our population differed from those in other locales in ways that may affect risk for coccidioidomycosis. Second, the study could not include case-patients who were asymptomatic or did not seek evaluation. Our study sample probably represents persons with more severe cases because all sought medical care from Kern Medical, the county healthcare facility. Moreover, nearly half of the casepatients reported overnight hospitalization. Thus, the epidemiologic patterns observed here may not apply to persons with milder cases that are likely to remain unrecognized. In addition, the Berkson bias (30) may 
yield observed ORs for agricultural exposures that underestimate true associations (i.e., if agricultural exposures cause pulmonary conditions other than coccidioidomycosis, such that those exposures are more prevalent in controls than they would otherwise be). Third, a low participation rate, especially among controls, may also have introduced selection bias. For example, if healthier control candidates were less likely to participate and had lower exposure levels contributing to their good health, our control sample would be biased toward higher exposures, leading to underestimation of true ORs. Alternatively, if healthier control candidates were more likely to participate and had lower exposure levels contributing to their good health, our control sample would be biased toward lower exposures, leading to overestimation of true ORs.

We were also unable to validate self-reported exposure information and clinical features. Hence, reporting bias may have affected our results, particularly if case-participants suspected that certain exposures might be important and overreported those. However, we are unaware of beliefs regarding coccidioidomycosis in this population that might affect reporting behavior, and we consider reporting bias an unlikely explanation of the observed associations.

On the basis of our findings, we recommend basic research on exposure, to include local soil sampling for Coccidioides spp. and area and personal respirable air sampling during harvest and other phases of cultivation, especially for root and bulb vegetable crops where exposure to surface and subsurface dust is likely. Although daunting from a practical standpoint, cohort studies of susceptible persons (i.e., based on nonreactive initial spherulin skin test) would help establish incidence and epidemiologic patterns while including persons contracting subclinical infections. Although the effectiveness of preventive recommendations remains uncertain (8), current recommendations $(27,31)$ for reducing dust exposure, including wetting soil and freshly harvested products, should be followed, especially for persons working with root and bulb vegetable crops. Personal respiratory protection, using NIOSH-approved equipment, should be encouraged. Because masks are more commonly used by women, educational programs should focus on improving acceptance among men and include evaluation of program effectiveness. Programs must also account for factors interfering with education and care that are common among the Hispanic agricultural worker population, including social marginalization associated with language, culture, and legal status and low levels of health insurance (32).

\section{Acknowledgments}

Special thanks to the Kern County farm workers who participated in this study and the Kern County Public Health Services Department.

This work was sponsored by the Centers for Disease Control and Prevention and NIOSH (U01 OH010839) and the Western Center for Agricultural Health and Safety (NIOSH grant U50 OH007550). H.B. was partly supported by the National Institutes of Health (grant UL1 TR001860).

\section{About the Author}

Dr. McCurdy is emeritus professor of public health sciences and internal medicine at the University of California, Davis, School of Medicine. His primary research interest is occupational health among agricultural workers.

\section{References}

1. Pappagianis D, Einstein H. Tempest from Tehachapi takes toll or Coccidioides conveyed aloft and afar. West J Med. 1978;129:527-30.

2. McCotter OZ, Benedict K, Engelthaler DM, Komatsu K, Lucas KD, Mohle-Boetani JC, et al. Update on the epidemiology of coccidioidomycosis in the United States. Med Mycol. 2019;57(Suppl_1):S30-40. https://doi.org/ 10.1093/mmy/myy095

3. Pearson D, Ebisu K, Wu X, Basu R. A review of coccidioidomycosis in California: exploring the intersection of land use, population movement, and climate change. Epidemiol Rev. 2019;41:145-57. https://doi.org/10.1093/ epirev/mxz004

4. California Department of Public Health. Epidemiologic summary of coccidioidomycosis in California, 2018 [cited 2019 Nov 19]. https:/ / www.cdph.ca.gov/Programs/CID/ DCDC/CDPH\%20Document\%20Library/ CocciEpiSummary2018.pdf

5. McCotter OZ, Chiller TM. Coccidioidomycosis (Valley fever) [cited 2020 Jan 2]. https://wwwnc.cdc.gov/travel/ yellowbook/2020/travel-related-infectious-diseases/ coccidioidomycosis-valley-fever

6. Freedman M, Jackson BR, McCotter O, Benedict K. Coccidioidomycosis outbreaks, United States and worldwide, 1940-2015. Emerg Infect Dis. 2018;24:417-23. https:// doi.org/10.3201/eid2403.170623

7. Galgiani JN, Ampel NM, Blair JE, Catanzaro A, Geertsma F, Hoover SE, et al. 2016 Infectious Diseases Society of America (IDSA) clinical practice guideline for the treatment of coccidioidomycosis. Clin Infect Dis. 2016;63:e112-46. https://doi.org/10.1093/cid/ciw360

8. Brown J, Benedict K, Park BJ, Thompson GR III. Coccidioidomycosis: epidemiology. Clin Epidemiol. 2013; 5:185-97.

9. Council of State and Territorial Epidemiologists. Public health reporting and national notification for coccidioidomycosis [cited 2020 Jan 2]. https:/ / cdn.ymaws.com/www.cste. org/resource/resmgr/PS/10-ID-04.pdf

10. Flynn NM, Hoeprich PD, Kawachi MM, Lee KK, Lawrence RM, Goldstein E, et al. An unusual outbreak of windborne coccidioidomycosis. N Engl J Med. 1979;301:358-61. https://doi.org/10.1056/ NEJM197908163010705 
11. Schneider E, Hajjeh RA, Spiegel RA, Jibson RW, Harp EL, Marshall GA, et al. A coccidioidomycosis outbreak following the Northridge, Calif, earthquake. JAMA. 1997;277:904-8. https://doi.org/10.1001/jama.1997.03540350054033

12. Werner SB, Pappagianis D, Heindl I, Mickel A. An epidemic of coccidioidomycosis among archeology students in northern California. N Engl J Med. 1972;286:507-12. https:/ / doi.org/10.1056/NEJM197203092861003

13. Wilken JA, Marquez P, Terashita D, McNary J, Windham G, Materna B; Centers for Disease Control and Prevention (CDC). Coccidioidomycosis among cast and crew members at an outdoor television filming event-California, 2012. MMWR Morb Mortal Wkly Rep. 2014;63:321-4.

14. Wilken JA, Sondermeyer G, Shusterman D, McNary J, Vugia DJ, McDowell A, et al. Coccidioidomycosis among workers constructing solar power farms, California, USA, 2011-2014. Emerg Infect Dis. 2015;21:1997-2005. https://doi.org/10.3201/eid2111.150129

15. Sondermeyer Cooksey GL, Wilken JA, McNary J, Gilliss D, Shusterman D, Materna BL, et al. Dust exposure and coccidioidomycosis prevention among solar power farm construction workers in California. Am J Public Health. 2017;107:1296-303. https://doi.org/10.2105/ AJPH.2017.303820

16. Nicas M. A point-source outbreak of coccidioidomycosis among a highway construction crew. J Occup Environ Hyg. 2018;15:57-62. https:/ / doi.org/10.1080/ 15459624.2017.1383612

17. Cummings KC, McDowell A, Wheeler C, McNary J, Das R, Vugia DJ, et al. Point-source outbreak of coccidioidomycosis in construction workers. Epidemiol Infect. 2010;138:507-11. https:/ / doi.org/10.1017/S0950268809990999

18. Das R, McNary J, Fitzsimmons K, Dobraca D, Cummings K, Mohle-Boetani J, et al. Occupational coccidioidomycosis in California: outbreak investigation, respirator recommendations, and surveillance findings. J Occup Environ Med. 2012;54:564-71. https://doi.org/10.1097/ JOM.0b013e3182480556

19. Wheeler C, Lucas KD, Derado G, McCotter O, Tharratt RS, Chiller T, et al. Risk stratification with coccidioidal skin test to prevent Valley fever among inmates, California, 2015. J Correct Health Care. 2018;24:342-51. https:/ / doi.org/ $10.1177 / 1078345818792679$

20. Sondermeyer GL, Lee LA, Gilliss D, Vugia DJ. Coccidioidomycosis-associated deaths in California, 20002013. Public Health Rep. 2016;131:531-5. https:/ / doi.org/10.1177/0033354916662210

21. Sondermeyer G, Lee L, Gilliss D, Tabnak F, Vugia D. Coccidioidomycosis-associated hospitalizations, California,
USA, 2000-2011. Emerg Infect Dis. 2013;19:1590-7. https://doi.org/10.3201/eid1910.130427

22. California Department of Food and Agriculture. California County Agricultural Commissioners' Reports, crop year 2016-2017 [cited 2019 Nov 1]. https:/ / www.cdfa.ca.gov/ statistics/pdfs/2017cropyearcactb00.pdf

23. Martin P, Hooker B, Akhtar M, Stockton M. How many workers are employed in California agriculture? Calif Agric. 2016;71:30-4 https:/ / doi.org/10.3733/ca.2016a0011

24. National Agricultural Workers Survey. Data tables 13 and 14 [cited 2019 Sep 21]. https:/ / www.doleta.gov/naws/ research/data-tables

25. Valley Fever Institute. Valley fever [cited 2019 Sep 21]. http://valleyfeverinstitute.com

26. Centers for Disease Control and Prevention (CDC). Coccidioidomycosis among persons attending the world championship of model airplane flying - Kern County, California, October 2001. MMWR Morb Mortal Wkly Rep. 2001;50:1106-7.

27. de Perio MA, Materna BL, Sondermeyer Cooksey GL, Vugia DJ, Su CP, Luckhaupt SE, et al. Occupational coccidioidomycosis surveillance and recent outbreaks in California. Med Mycol. 2019;57(Suppl_1):S41-5. https://doi.org/10.1093/mmy/myy031

28. McCurdy SA, Stoecklin-Marois MT, Tancredi DJ, Bennett $\mathrm{DH}$, Schenker MB. Region of birth, sex, and agricultural work of immigrant Latino farm workers: the MICASA study. J Agric Saf Health. 2014;20:79-90.

29. Bowen LE. Does that face mask really protect you? Appl Biosaf. 2010;15:67-71. https:/ / doi. org/10.1177/153567601001500204

30. Rothman KJ, Greenland S, Lash TL. Validity in epidemiologic studies. In: Rothman KJ, Greenland S, Lash TL, editors. Modern epidemiology. Philadelphia: Lippencott Williams \& Wilkins; 2008. p 135-6.

31. Hazard Evaluation System and Information Service. Preventing work-related coccidioidomycosis (Valley fever) [cited 2019 Nov 19]. https:/ / www.cdph.ca.gov/Programs/ CCDPHP/DEODC/OHB/HESIS/CDPH\%20Document\%20 Library/CocciFact.pdf

32. Villarejo D, McCurdy SA, Bade B, Samuels S, Lighthall D, Williams D III. The health of California's immigrant hired farmworkers. Am J Ind Med. 2010;53:387-97. https:/ / doi.org/ 10.1002/ajim.20796

Address for correspondence: Stephen A. McCurdy, Department of Public Health Sciences, MS-1C Rm 126, University of California,

Davis, Davis, CA 95616-8638, USA; email: samccurdy@ucdavis.edu 